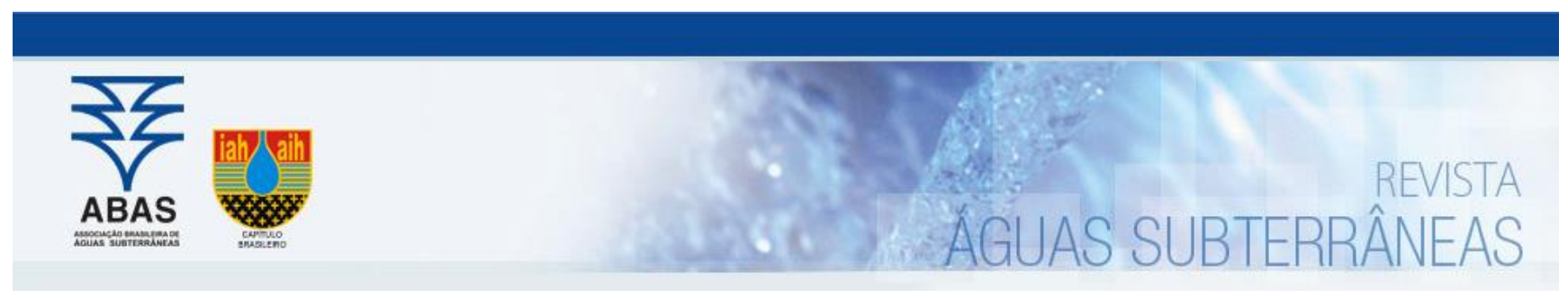

Artigos

\title{
Análise da capacidade de infiltração para atenuação de alagamento em um ponto crítico na cidade do Recife
}

\section{Analysis of infiltration capacity to attenuate flooding at a critical location in the city of Recife}

\author{
Suellem Attila Parisi ${ }^{1}$; Willames de Albuquerque Soares ${ }^{1}$; Cícero de Deus Rosa Filho ${ }^{1} \bowtie$ \\ 1 Universidade de Pernambuco/ Escola Politécnica de Pernambuco (UPE/POLI), Recife, PE \\ $\triangle$ suellem.parisi@gmail.com,was@poli.br, cicerofilho@outlook.com
}

Palavras-chave:

Beerkan.

Hydrus 1D.

Águas subterrâneas.

Simulação.

Precipitação.

\begin{abstract}
Resumo
A crescente urbanização de Recife (PE) acarreta em uma diminuição das áreas naturais permeáveis, aumento do escoamento superficial, redução na recarga das águas subterrâneas e geração de alagamentos que, embora pontuais ocasionam diversos transtornos à população. Esse cenário, juntamente com a deficiência no sistema de drenagem local, cria a necessidade de estudos de técnicas sustentáveis para minimizar os impactos dos eventos chuvosos. Sendo assim, o objetivo desse trabalho foi estimar o comportamento hidrodinâmico de um solo da cidade do Recife utilizando registros reais de precipitação, a fim de verificar seu potencial de infiltração na atenuação de alagamentos e seus consequentes benefícios para o abastecimento do fluxo subterrâneo próximo a um ponto de alagamento. Para isso, foi escolhida a área coberta por solo natural adjacente a um local crítico em época chuvosa. As características hidrodinâmicas do solo foram estimadas a partir da metodologia Beerkan. No software Hydrus 1D, as simulações foram realizadas com os dados meteorológicos do mês de julho de 2000 e consideraram a situação mais desfavorável de infiltração, ou seja, menor condutividade hidráulica saturada obtida ( $K \mathrm{~s}=0,0047 \mathrm{~mm} / \mathrm{s}$ ). As simulações mostraram a influência de Ks nos resultados que evidenciaram que o solo possuía uma boa capacidade drenante a curto e médio prazo, conforme as análises diárias e mensal, além de ter se observado benefícios para o abastecimento humano e para as obras civis devido a ocorrência da recarga do nível freático.
\end{abstract}

Abstract

Keywords:

Beerkan.

Hydrus 1D.

Groundwater.

Simulation.

Precipitation.

Revisado por pares.

Recebido em: 09/02/2020.

Aprovado em: 20/07/2020.

\begin{abstract}
The growing urbanization of Recife (PE) leads to a decrease in permeable natural areas, increased runoff, reduced groundwater recharge and the generation of floods that, although punctual, cause various disturbances to the population. This scenario, together with the deficiency in the local drainage system, creates the need for studies of sustainable techniques to minimize the impacts of rainy events. Therefore, the objective of this work was to estimate the hydrodynamic behavior of a soil in the city of Recife using real precipitation records, in order to verify its infiltration potential in the attenuation of floods and its consequent benefits for the supply of the underground flow close to a flooding point. For this, the area covered by natural soil adjacent to a critical location in the rainy season was chosen. The hydrody namic characteristics of the soil were estimated using the Beerkan methodology. In the Hydrus 1D software, the simulations were performed with the meteorological data for the month of July 2000 and considered the most unfavorable infiltration situation, that is, the lowest saturated hydraulic conductivity obtained (Ks $=0.0047 \mathrm{~mm} / \mathrm{s}$ ). The simulations showed the influence of Ks in the results that showed that the soil had a good draining capacity in the short and medium term, according to the daily and monthly analyzes, in addition to the benefits for human supply and civil works due to the occurrence of recharging the water table.
\end{abstract}

DOI: http:/dx.doi.org/10.14295/ras.v34i2.29494

\section{INTRODUÇÃO}

Nos últimos séculos a população urbana vem sofrendo um crescimento exponencial (UNITED NATIONS, 2008) e, como consequência, tem ocorrido uma alteração do uso do solo (NAZEM E HASSAN, 2016; GUO, 2013). À medida que as áreas urbanas aumentam, o solo com vegetação é convertido em coberturas impermeáveis modificando significativamente o balanço hídrico e gerando um aumento do escoamento superficial (GUO, 2013; CAMPANA, 2001).
Tais modificações podem impactar o ambiente das bacias hidrográficas, pois alteram os processos hidrológicos, como infiltração, recarga de águas subterrâneas e escoamento superficial, podendo levar a situações de alagamentos e inundações (NIEHOFF, BRONSTERT, BURGER, 2002). No intuito de evitar tais situações, os projetistas, de um modo geral, recorrem a obras estruturantes, muitas vezes inviabilizadas por seu alto custo e complexidade de execução. 
Sendo assim, pesquisadores destacaram a aplicação do conceito de drenagem sustentável (MOURA E SILVA, 2015; MOLINA, ENOUT E REDA, 2018; FABRICIO et al., 2019). Tal conceito faz referência à utilização das áreas permeáveis, como o solo natural, para aplicação das chamadas técnicas compensatórias que objetivam atenuar a ocorrência de alagamentos e/ou inundações. Além disso, algumas delas propiciam um aumento da recarga subterrânea, fato importante, visto que em algumas regiões esse abastecimento é realizado pelas águas subterrâneas.

Entretanto, os solos naturais em áreas urbanas sofreram várias alterações devido à mistura com detritos de demolição, processos de corte e de aterro e compactação (SCHIFMAN E SHUSTER, 2019). Além disso, a hidrologia dos solos urbanos acrescenta complexidade para previsão do escoamento superficial e ainda não possuem avaliação de maneira estruturada (SHUSTER et al., 2014).

A fim de um maior entendimento sobre o potencial do solo para tais finalidades, diversos fatores devem ser considerados, como relevo, uso, ocupação e características hidráulicas (PIRKHOFFER, CZIGÁNY E GERESDI, 2009), tendo em vista sua relação com a capacidade de infiltração, condução e retenção de água. No mais, a precipitação também é um fenômeno fundamental para o desencadeamento de alagamentos e inundações.

Isto posto, a análise conjunta do comportamento desses elementos propicia o conhecimento acerca da dinâmica da água no solo e, consequentemente, sua capacidade de geração de escoamento superficial, influenciando no potencial de ocorrência das situações extremas.

Hillel (1998) apontou que a descrição da dinâmica da água no solo em campo demanda o conhecimento de suas características hidráulicas, abrangendo a relação prática entre a condutividade hidráulica, o potencial matricial e a umidade do solo. Entretanto, a obtenção direta dessas propriedades demanda a coleta de vários dados e ensaios laboratoriais muitas vezes demorados e onerosos.

Portanto, diversos autores apresentaram o uso de métodos indiretos, a exemplo da metodologia Beerkan que propõe a estimativa de tais parâmetros com base em propriedades do solo de obtenção mais fácil, mais ágil e menos onerosa (HAVERKAMP et al., 1994; LASSABATÈRE et al., 2006; DI PRIMA et al., 2016).

Do mesmo modo, outros trabalhos apresentaram o uso de métodos computacionais, a exemplo do software Hydrus 1D (SIMUNEK et al., 2013), que permitem estimar os processos da dinâmica da água no solo e sua interação com a atmosfera a partir de considerações da metodologia do balanço hídrico
(COUTINHO et al., 2016; URSULINO et al., 2019). Alves et al. (2012) indicaram que a facilidade de execução, os baixos custos e a rápida obtenção dos resultados são as principais vantagens das simulações numéricas.

No contexto de áreas urbanas com deficiência na drenagem, pode-se destacar o Recife, situada no estado de Pernambuco, região Nordeste do Brasil, onde eventos chuvosos ocasionam alagamentos e inundações. Localizada pouco acima o nível no mar, cerca de 2 a 10 metros, a cidade possui áreas com níveis equivalentes aos das marés de sizija (MELO, 2014). Além disso, a cidade é circundada por morros e elevações topográficas que proporcionam o acúmulo de água em seu interior por dificultar a drenagem natural em épocas chuvosas, resultando em 159 pontos críticos de alagamento, cadastrados no ano de 2013 (EMLURB, 2013).

Com esse cenário e considerando a complexidade de implantação de obras estruturantes na cidade, a aplicação de práticas sustentáveis, associada ao sistema de drenagem do município, configura-se como essencial para a atenuação dos efeitos causadores dos alagamentos. Contudo, poucos são os estudos que estimam a dinâmica da água no solo utilizando registros reais de precipitação, especialmente no Brasil e, mais especificamente, em áreas urbanas, como o estado de Pernambuco. Sendo assim, este estudo teve como objetivo estimar o comportamento hidrodinâmico de um solo da cidade do Recife, utilizando registros reais de precipitação a fim de verificar seu potencial de infiltração atenuação de alagamentos e seus consequentes benefícios para o abastecimento do fluxo subterrâneo.

\section{MATERIAIS E MÉTODOS}

\subsection{Local de estudo}

A escolha da área de estudo teve como base o cadastramento dos pontos críticos de alagamento da cidade (EMLURB, 2013) (Figura 1) e a existência de área permeável próxima ao local. Devido a grande urbanização da cidade, muitos pontos críticos não possuíam área permeável próxima. A área escolhida localiza-se no Bairro de Areias, na Região Metropolitana da cidade do Recife, estado de Pernambuco (Figura 2). Conforme o cadastramento, dentre os 42 bairros com registro de pontos críticos, o bairro de Areias possui 5 pontos, assim como os bairros de Casa Forte, Encruzilhada e Imbiribeira. Nove bairros apresentam um maior número de pontos e 29 um menor número. 0 município possui um clima tropical quente e úmido do tipo As, conforme classificação climática de Köppen, a temperatura média histórica anual do município é de $23,9^{\circ} \mathrm{C}$, e a média histórica anual da precipitação é de 2.254 mm (MELO, 2014). 
Figura 1 - Mapa de localização da região de estudo e dos pontos de alagamentos no Recife

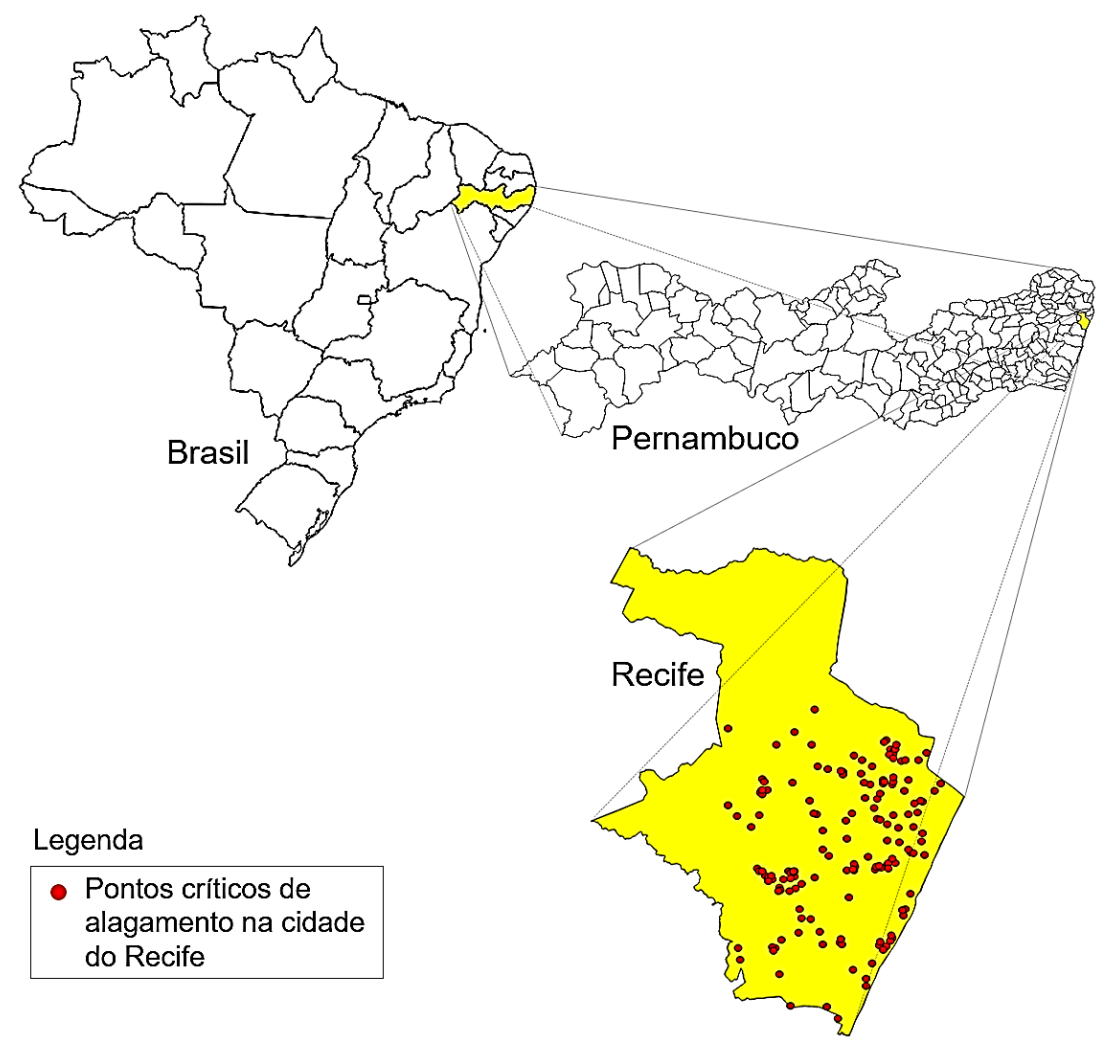

Figura 2 - Mapa de localização do ponto de alagamento selecionado para estudo
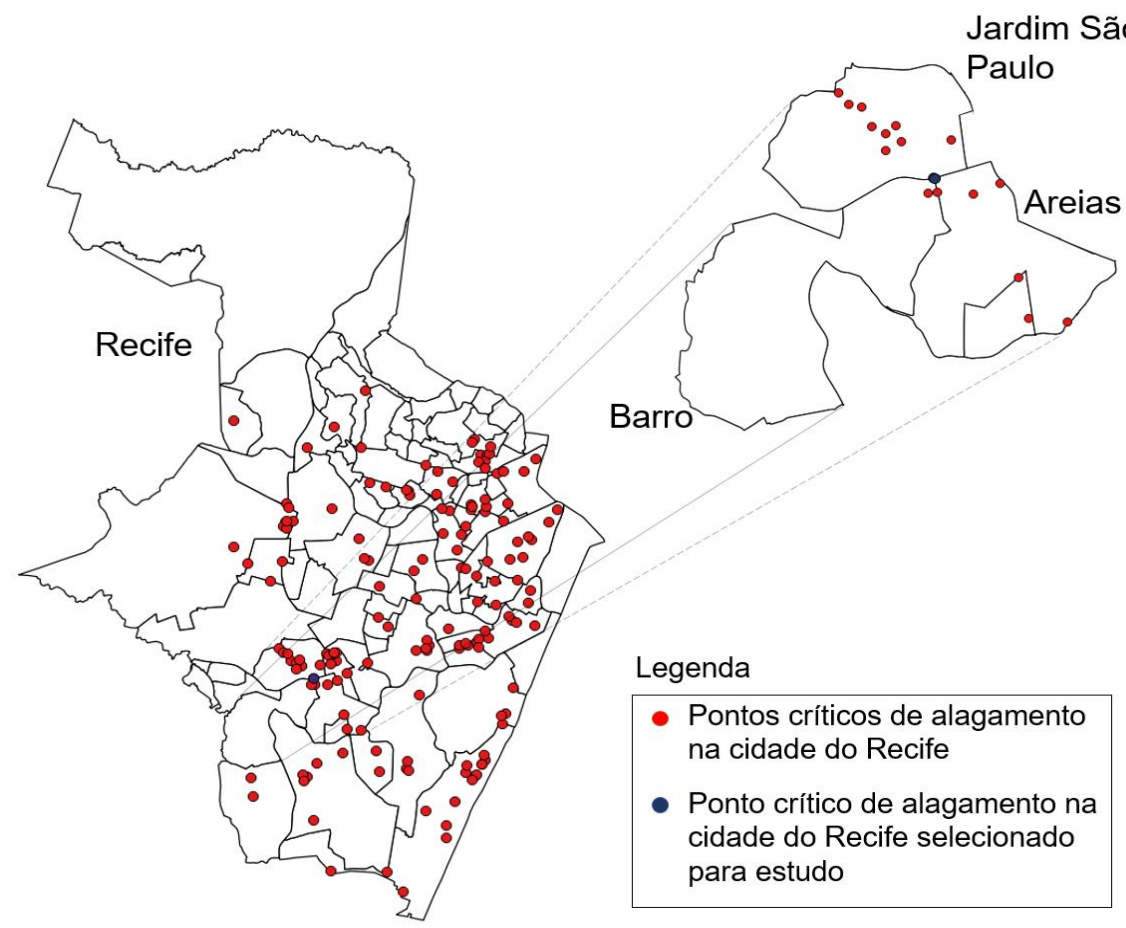

O ponto de alagamento encontra-se abaixo de um pontilhão e, próximo a ele, a área permeável de aproximadamente 9.000 $\mathrm{m}^{2}$ está em um terreno sem vegetação densa. Para estudo das características do solo, foram definidos três pontos no ter- reno $(A, B, C)$ onde foram realizados ensaios em campo e coletadas amostras, a $10 \mathrm{~cm}$ de profundidade, para ensaios em laboratório. Os pontos A e B distam $51,82 \mathrm{~m}$, os pontos B e C 53,05 m e A e C 98,71 m (Figura 3). 
Figura 3 - Vista da área permeável e do ponto de alagamento destacados

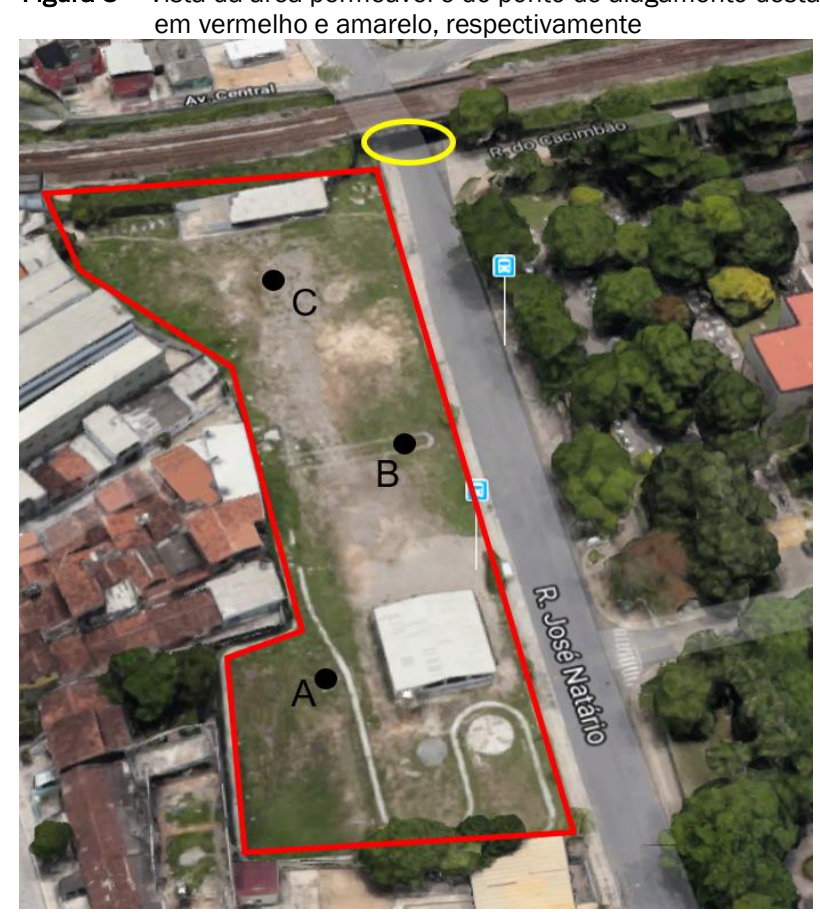

\subsection{Processo para caracterização hidrodinâmica do solo}

Objetivando avaliar o desempenho do solo existente na área selecionada, foram estimados os parâmetros hidrodinâmicos. A obtenção desses parâmetros foi conduzida pela metodologia Beerkan, criada por Haverkamp et al. (1994). No Brasil, tal metodologia tornou-se mais difundida a partir do algoritmo denominado Beerkan Estimation Soil Transfer - BEST, desenvolvido por Lassabatère et al. (2006), utilizado com êxito por diversos autores (SOUZA et al., 2008; SANTOS, SILVA E SILVA, 2012; SALES E ALMEIDA, 2015; SANTOS et al., 2018) e aplicado neste estudo.

0 método Breekan utiliza a equação proposta por van Genuchten (1980) combinada com a hipótese de Burdine (1953) para o cálculo da curva de retenção de água (Equação 1) e a equação proposta por Brooks \& Corey (1964) para o cálculo da condutividade hidráulica (Equação 2).

$$
\begin{aligned}
& \theta(h)=\frac{\theta-\theta_{r}}{\theta_{s}-\theta_{r}}=\left[1+\left(\frac{h}{h_{g}}\right)^{n}\right]^{-m}, m=1-\frac{2}{n}, \quad n>2 \\
& K(\theta)=K_{s}\left(\frac{\theta-\theta_{r}}{\theta_{s}-\theta_{r}}\right)^{\eta}
\end{aligned}
$$

Onde:

$\theta$ - umidade volumétrica efetiva;

$\theta_{r}$ - umidade volumétrica residual;

$\theta_{\mathrm{s}}$ - umidade volumétrica na saturação;

$\mathrm{h}$ - potencial matricial;

$h_{g}$ - parâmetro de ajuste que depende da estrutura do solo;

m - parâmetro de forma;

$\mathrm{n}$ - parâmetro de forma; $\eta$ - parâmetro de forma;

$K(\theta)$ - condutividade hidráulica dos poros do solo em função de $\theta$;

$\mathrm{K}_{\mathrm{s}}$ - condutividade hidráulica saturada.

Tendo como fundamentos principais os ensaios de infiltração simplificado e as análises da distribuição do tamanho das partículas do solo, são imprescindíveis algumas informações provenientes de tais ensaios para estimar os parâmetros. Os dados de entrada para execução do algoritmo BEST são: distribuição do tamanho das partículas do solo, curva de infiltração da lâmina acumulada no tempo, densidade do solo, densidade de partículas, umidade inicial do solo e raio do infiltrômetro.

Os seguintes ensaios em campo e em laboratório foram realizados para obtenção desses dados:

Análise granulométrica: Com as amostras coletadas nos três pontos definidos para estudo, foram realizadas as análises de granulometria conforme normatizados pela Norma Brasileira - NBR 7181/2016 (ABNT, 2016). Para a quantificação da distribuição do tamanho das partículas individuais de minerais do solo conforme seus diâmetros, a NBR estabelece o método para análise granulométrica de solos, realizada por peneiramento ou por uma combinação de sedimentação e peneiramento (ABNT, 2016). No presente estudo, utilizou-se a combinação citada.

Ensaio de infiltração: Utilizou-se o infiltrômetro com anel simples, como determinado pela metodologia Beerkan, que, devido à sua facilidade e maior agilidade de execução, foi empregado em diversos estudos (BAGARELLO, IOVINO E ELRICK, 2004; SOUZA et al., 2008; SOARES, 2010; SILVA JUNIOR, SILVA e SOARES, 2016). Precedendo o ensaio, realizado ao lado dos três pontos onde foram coletadas as amostras, fez- 
se uma limpeza superficial e, em seguida, o infiltrômetro, com $150 \mathrm{~mm}$ de diâmetro, foi cravado no solo de forma a assegurar um fluxo vertical de água. No interior do infiltrômetro adicionava-se um volume fixo de $50 \mathrm{ml}$ de água, equivalente a uma lâmina de 3,96 mm, à medida que a água infiltrava, ou seja, quando o solo ficava exposto. Os tempos decorridos entre os despejos de água eram cronometrados e anotados. A repetição desse processo se deu até o estado estacionário.

Ensaio de densidade do solo: 0 método de determinação da massa específica do solo visa medir essa propriedade através de um volume conhecido do solo. 0 processamento do ensaio se deu com a coleta de amostras indeformadas por meio de um cilindro de volume interno conhecido através do coletor de Uhland. A amostra foi acondicionada em recipientes de metal com tampa, vedada com fita isolante e pesada em laboratório antes e após o processo de secagem. 0 procedimento do cálculo é realizado conforme definido pelo método do cilindro volumétrico (EMBRAPA, 2017).

Ensaio de densidade de partículas: Visou medir a densidade média das partículas minerais e orgânicas na amostra de solo, refletindo sua composição média. Essa densidade se relaciona ao volume efetivamente ocupado por matéria sólida, desconsiderando a porosidade. Os ensaios de densidade das partículas foram realizados conforme o método do balão volumétrico, definido pela EMBRAPA (2017). A massa da amostra foi obtida por meio de pesagem antes e após ser seca em estufa. A determinação do volume da amostra foi obtida através da diferença entre o volume de álcool etílico necessário para preencher um recipiente calibrado vazio e o volume do líquido necessário para completar o volume do recipiente contendo a amostra seca.

Ensaio de umidade: 0 ensaio da umidade tem como princípio determinar a massa de água presente na amostra durante as condições de coleta. Para isso, anteriormente ao início do ensaio de infiltração, nas proximidades dos locais de cravação do infiltrômetro, foram coletadas amostras de solo à cerca de $5 \mathrm{~cm}$ de profundidade para determinação da umidade volumétrica inicial. Todas as amostras foram acondicionadas em recipientes de metal com tampa e vedadas com fita isolante para manter as condições nas quais foram coletadas. No laboratório, as amostras foram pesadas, colocadas em estufa e, ao final do processo de perda de água, foram novamente pesadas. Com o tratamento dos dados, foram determinados os teores de umidade, conforme definido pelo Manual de Métodos de Análise de Solo (EMBRAPA, 2017).

Porosidade total: Obtida através do método indireto, definido pela Embrapa (2017), utilizando a densidade do solo $\left(\rho_{\mathrm{s}}\right)$ e a densidade das partículas $\left(\rho_{\mathrm{p}}\right)$.

\subsection{Determinação dos dados de entrada e condições de con- torno para as simulações computacionais}

As simulações da dinâmica unidimensional da água no solo e o fluxo da água na parte inferior desse solo foram realizadas no software Hydrus 1D a partir dos dados de entrada e condições de contorno definidos:
Profundidade e número de camadas do solo: o terreno estudado é cortado pelo Canal Guarulhos a uma profundidade média de 1,13 m, em relação ao nível o solo, segundo cadastramento de macrodrenagem da cidade. Portanto, devido à existência do Canal, foi admitida uma única camada de $1 \mathrm{~m}$ de constituição homogênea.

Modelo de cálculo dos parâmetros e das propriedades hidrodinâmicos: dentre os seis modelos disponíveis no software, foi adotado o modelo de van Genuchten (1980) combinado com a hipótese de Mualem (1976) (Equação 3). Patil e Singh (2016) afirmaram que estudos tentaram, sem êxito, desenvolver uma função universal para estimar as características hidrodinâmicas para qualquer tipo de solo. Diante disso, o modelo de van Genuchten tem sido o mais usado por autores (LIANG et al., 2016; WALLOR, ROSSKOPF e ZEITZ, 2018; TIAN et al., 2019; LUO et al., 2019; SHENG et al., 2019; LATORRE E MORET-FERNÁNDEZ, 2019) e, por isso, foi adotado neste estudo.

$\theta(h)=\frac{\theta-\theta_{r}}{\theta_{s}-\theta_{r}}=\left[1+\left(\frac{h}{h_{g}}\right)^{n}\right]^{-m}, m=1-\frac{1}{n}, n>1$

Onde:

$\theta$ - umidade volumétrica efetiva;

$\theta_{r}$ - umidade volumétrica residual;

$\theta_{s}$ - umidade volumétrica na saturação;

$\mathrm{h}$ - potencial matricial;

$h_{g}$ - parâmetro de ajuste que depende da estrutura do solo;

$\mathrm{m}$ - parâmetro de forma;

$\mathrm{n}$ - parâmetro de forma.

Valor dos parâmetros e das propriedades hidrodinâmicas do solo: as variáveis relacionadas às propriedades hidráulicas variam conforme o modelo de cálculo selecionado. Para o modelo de van Genuchten com Mualem, foi necessário informar cinco parâmetros: umidade volumétrica residual $\left(\theta_{\mathrm{r}}\right)$, umidade volumétrica saturada $\left(\theta_{\mathrm{s}}\right)$, parâmetro de ajuste da curva de retenção de água $(\alpha)$, parâmetro de forma da curva de retenção de água $(n)$ e condutividade hidráulica saturada $\left(K_{s}\right)$. Tais parâmetros foram estimados através da metodologia Beerkan. Contudo, a metodologia Beerkan com uso do BEST estima os parâmetros hidrodinâmicos a partir do modelo de van Genuchten (1980) combinado com a hipótese de Burdine (1953) (Equação 1). Para ajustar os dados de entrada à hipótese de Mualem (1976) (Equação 3), foi utilizado o software Retention Curve - RETC (VAN GENUCHTEN, LEIJ E YATES, 1991), assim como foi feito por Ursulino et al. (2019).

Condição de limite superior do fluxo de água: estabeleceu-se a condição de contorno atmosférico com camada superficial. Esta condição permite que a água se acumule na superfície, onde, aqui, admitiu-se uma altura máxima de $2 \mathrm{~m}$. A altura da camada de água superficial aumenta devido à precipitação pluviométrica e reduz devido à infiltração e evaporação.

Condição de limite inferior do fluxo de água: determinou-se como condição de contorno inferior a drenagem livre. Esta condição estabelece um limite de gradiente zero que pode ser 
usada para simular um perfil de solo que drena livremente. Ou seja, toda água que chega à base do perfil deve ser drenada ou removida e não acumulada na base do perfil.

Condição inicial: foi especificada em termos de teor de água, de forma que a umidade inicial do solo foi considerada variável ao longo do perfil de $1 \mathrm{~m}$ de profundidade do solo. Assim sendo, a camada de $10 \mathrm{~cm}$ próxima à superfície possuía umidade igual à umidade residual $\left(\theta_{r}\right)$, estimada pela metodologia Beerkan. A cada $10 \mathrm{~cm}$, foi admitido um aumento gradual de forma que a camada na profundidade de $90 \mathrm{~cm}$ a $1 \mathrm{~m}$ possuía umidade igual à umidade saturada $\left(\theta_{\mathrm{s}}\right)$, também estimada pela metodologia.

Condições meteorológicas: foram consideradas a precipitação, temperatura máxima, temperatura mínima, umidade, velocidade do vento e insolação durante o período do mês estudado. No estado de Pernambuco existem postos de monitoramento de chuvas cujas localizações estão disponíveis no site da Agência Pernambucana de Águas e Climas - APAC. Os dados históricos de precipitação foram obtidos da Estação da Várzea, $n^{\circ} 30$, por ser a estação com dados disponíveis mais próxima do ponto de alagamento estudado, aproximadamente $7 \mathrm{~km}$. Já os demais dados foram obtidos da Estação do Curado, $\mathrm{n}^{\circ} 82900$, por ser a única da cidade a registrar essas informações, segundo o site do Instituto Nacional de Meteoro- logia - INMET. Para a simulação, foram considerados os dados meteorológicos do mês mais chuvoso dentro do ano mais chuvoso, conforme análise do histórico de precipitação desde o ano de 1994 até 2018, obtido na Estação da Várzea. Portanto, com uma precipitação de $3.482 \mathrm{~mm}$, o ano de 2000 apresentou-se como o ano mais chuvoso, diferentemente do ano de 1998 que teve o menor valor acumulado, $1.255,4 \mathrm{~mm}$. Assim, com 650,9 mm de chuva, o mês de julho do referido ano foi utilizado na simulação.

\section{RESULTADOS E DISCUSSÕES}

\subsection{Ensaios de campo e de laboratório}

Os percentuais de areia, silte e argila, a densidade do solo $\left(\rho_{\mathrm{s}}\right)$, a densidade das partículas $\left(\rho_{p}\right)$, a porosidade total $(\varphi)$ e a classificação textural estão apresentados na Tabela 1 para cada ponto definido no terreno. A textura do solo foi feita conforme as classes definidas pelo Departamento de Agricultura dos Estados Unidos (USDA). As frações de areia foram preponderantes em todos os pontos, apresentando-se em maior percentual em B e em menor em A. Sendo assim, a variação nos percentuais gerou uma classificação textural distinta dentro do solo estudado. 0 maior percentual de argila no ponto A garantiu uma textura franco argilo arenoso para o mesmo.

Tabela 1 - Percentual de areia, silte e argila, densidade do solo ( $\rho s)$, densidade das partículas $\left(\rho_{\mathrm{p}}\right)$, porosidade total $(\varphi)$ e classificação textural para cada ponto ensaiado

\begin{tabular}{cccccccc}
\hline Pontos & $\begin{array}{c}\text { Areia } \\
(\%)\end{array}$ & $\begin{array}{c}\text { Silte } \\
(\%)\end{array}$ & $\begin{array}{c}\text { Argila } \\
(\%)\end{array}$ & $\begin{array}{c}\rho_{\mathrm{s}} \\
\left(\mathrm{g} / \mathrm{cm}^{3}\right)\end{array}$ & $\begin{array}{c}\rho_{\mathrm{p}} \\
\left(\mathrm{g} / \mathrm{cm}^{3}\right)\end{array}$ & $\begin{array}{c}\boldsymbol{(} \\
(\%)\end{array}$ & Textura \\
\hline A & 64,2 & 13,6 & 22,2 & 1,79 & 2,62 & 32 & Franco argilo arenoso \\
B & 75,6 & 11,6 & 12,8 & 1,43 & 2,55 & 44 & Franco arenoso \\
C & 68,1 & 13,1 & 18,8 & 1,86 & 2,58 & 28 & Franco arenoso \\
\hline
\end{tabular}

0 ponto $C$ apresentou valor de $\rho_{\mathrm{s}}$ acima do limite de 1,20 a $1,80 \mathrm{~g} / \mathrm{cm}^{3}$ definido por Brady (1989) para solos com textura franco arenosa. Tal valor é uma possível consequência do eventual estacionamento de veículos, visto que o terreno não possui barreira física que impeça o acesso de alguns carros. Esse fato eleva o grau de compactação reduzindo assim $\varphi$, como constado em outros estudos (STRECK et al., 2004; GOMES et al., 2019). Ainda segundo Brady (1989), a faixa da $\rho_{p}$ de solos minerais está entre 2,60 a $2,75 \mathrm{~g} / \mathrm{cm}^{3}$. Valores infe- riores, como os resultantes no ponto B e C, podem estar relacionados com a presença de matéria orgânica que contribui para uma redução no valor da densidade de partículas devido a sua menor massa por unidade de volume em relação às partículas minerais (JONES, 1983; MANRIQUE E JONES, 1991).

Pelas curvas de infiltração (Figura 4) pode-se verificar uma variação considerável na inclinação das curvas, isto é, na velocidade de infiltração de água no solo. 
Figura 4 - Curvas de infiltração
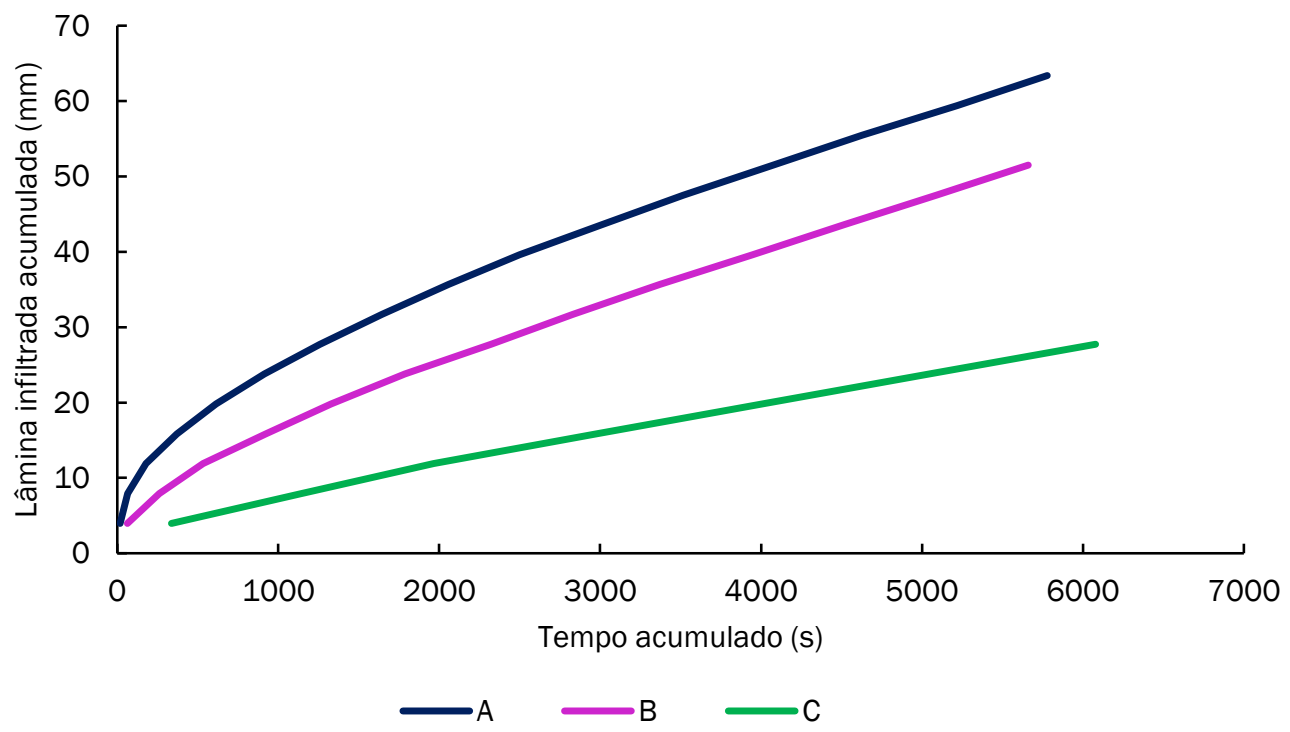

No ponto A foi observada a maior taxa de infiltração, 39,49 $\mathrm{mm} / \mathrm{h}$. Já em C, a taxa foi de $16,42 \mathrm{~mm} / \mathrm{h}$, a menor. Sendo assim, ainda que a infiltração represente um processo dependente de diferentes características físicas e morfológicas do solo, como verificado em diversos estudos (REZENDE e SCALOPPI, 1985; WALKER E SKOGERBOE, 1987; FRIZZONE, 1993), no ponto C, a compactação do solo pode ter tido grande contribuição na redução da taxa de infiltração (CAMARGO e ALLEONI, 1997; ROSOLEM, FOLONI E TIRITAN, 2002; ANTONELI E TOMAZ, 2009).

\subsection{Caracterização hidrodinâmica do solo}

Os parâmetros de forma e as propriedades hidrodinâmicas referentes à metodologia Beerkan (Equação 1 e Equação 2) estão na Tabela 2. A condutividade hidráulica saturada $\left(\mathrm{K}_{\mathrm{s}}\right)$ apresentou considerável variação nos pontos. Tendo maior valor em C $(0,0083 \mathrm{~mm} / \mathrm{s})$ e menor em A $(0,0047 \mathrm{~mm} / \mathrm{s})$.

Tabela 2 - Parâmetros de forma e propriedades hidrodinâmicas para a metodologia Beerkan

\begin{tabular}{cccccc}
\hline Ponto & $\theta_{\mathrm{s}}\left(\mathrm{cm}^{3} / \mathrm{cm}^{3}\right)$ & $\mathrm{K}_{\mathrm{s}}(\mathrm{mm} / \mathrm{s})$ & $\mathrm{n}$ & $\mathrm{m}$ & $\boldsymbol{\eta}$ \\
\hline A & 0,3177 & 0,0047 & 2,1475 & 0,0687 & 16,5966 \\
B & 0,4407 & 0,0049 & 2,2061 & 0,0934 & 12,7059 \\
C & 0,2721 & 0,0083 & 2,1740 & 0,0800 & 14,5018 \\
\hline
\end{tabular}

\section{Onde:}

$\theta_{s}$ - umidade volumétrica na saturação;

$\mathrm{K}_{\mathrm{s}}$ - condutividade hidráulica saturada;

$\mathrm{n}$ - parâmetro de forma;

$\mathrm{m}$ - parâmetro de forma;

$\eta$ - parâmetro de forma.

No Agreste de Pernambuco, em solo com texturas franco e franco arenosa, Montenegro e Montenegro (2006), verificaram uma condutividade hidráulica saturada média de 0,0825 $\mathrm{mm} / \mathrm{s}$ e coeficiente de variação de $214 \%$. No mesmo estado, um solo dominantemente franco arenoso resultou em um valor médio de $0,0337 \mathrm{~mm} / \mathrm{s}$ e coeficiente de variação de $261 \%$ (SANTOS et al., 2012). Já no Rio Grande do Sul, uma área com predominância de solo franco arenoso e presença de franco argiloso apresentou média de $0,0295 \mathrm{~mm} / \mathrm{s}$ e menor coeficiente (62,7\%) (ABREU et al., 2003). Esses estudos tinham como objetivo analisar a variabilidade da condutividade hidráulica saturada e, para isso, fizeram uso de uma grande quantidade de amostras de solo: 59 (MONTENEGRO E MONTENEGRO, 2006), 196 (SANTOS et al., 2012) e 110 (ABREU et al., 2003). Tomando como referência a classificação de varia- bilidade das propriedades do solo definida por Warrick e Nielsen (1980), todos esses estudos observaram uma alta variabilidade espacial para $\mathrm{K}_{\mathrm{s}}$, corroborando com outros estudos (WARRICK E NIELSEN, 1980; MESQUITA E MORAES, 2004; SEPASKHAH E ATAEE, 2004; SOBIERAJ, ELSENBEER E CAMERON, 2004). Sendo assim, verifica-se que não existe uma faixa de valor para tal parâmetro.

Analogamente, foi observada uma variação na umidade volumétrica saturada $\left(\theta_{s}\right)$ que apresentou maior valor no ponto $B$. Essa variação é consequência da estrutura do solo, ou seja, seu arranjo poroso (PACHECO, REICHARDT E TUON, 1994).

Enquanto os parâmetros de forma " $n$ " e "m" apresentaram maiores valores no ponto $B$, o parâmetro " $n$ " apresentou menor valor (Tabela 2). Tais parâmetros estão relacionados com a distribuição granulométrica, de modo que, quanto maior o diâmetro das partículas, maior o valor de $n$ e $m$ e menor o $n$ (LASSABATÈRE et al., 2006; SANTOS, SILVA E SILVA, 2012). Esse resultado confirma o que foi apresentado na Tabela 1, onde se verifica que o valor de $n$ e $m$ apresentam-se diretamente proporcionais aos percentuais de areia. 
As curvas de retenção $(\theta(h))$ mostram relativa dispersão a medida que o valor do potencial mátrico (h) diminui (Figura 5). Isto se dá devido à grande influência da textura e da estrutura do solo na capacidade de retenção de água (KLEIN; LIBARDI, 2000).
Portanto, os solos pertencentes a mesma classe textural podem apresentar curvas distintas devido às variações na distribuição do tamanho de partículas, assim como nas diferenças no teor de matéria orgânica, tipo de argila e diferenças de microestrutura.

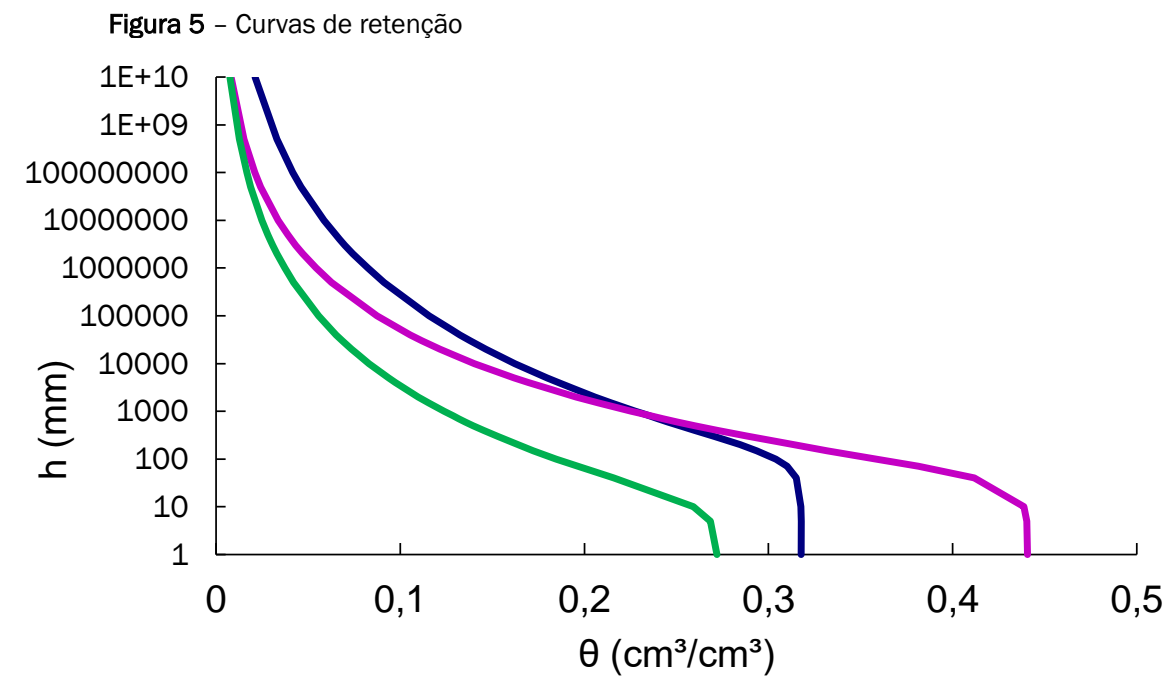

$-\mathrm{A} \quad \mathrm{B}-\mathrm{C}$

Alguns estudos assumiram a condutividade hidráulica como log-normalmente distribuída durante a análise hidrológica do solo (WOODBURY E SUDICKY, 1991; ISTOK et al., 1994; BOSCH E WEST, 1998) ainda que a normalidade de tal propriedade já tenha sido verificada (VIEIRA, NIELSEN E BIGGAR, 1981). Sendo assim, a Figura 6 exibe a curva de condutivi- dade hidráulica $(K)$, em função da umidade $(\theta)$, sem considerar a escala logarítmica. Os pontos apresentaram curvas distintas devido à alta variabilidade dos parâmetros. $\mathrm{O}$ ponto $\mathrm{C}$ atingiu um alto valor de $\mathrm{K}_{\mathrm{s}}(29,88 \mathrm{~mm} / \mathrm{h})$ ao atingir a menor $\theta_{\mathrm{s}}\left(0,2721 \mathrm{~cm}^{3} / \mathrm{cm}^{3}\right)$. Já $A$ e $B$ alcançam seu $K_{s}$ em valores consideravelmente distintos de $\theta_{\mathrm{s}}$

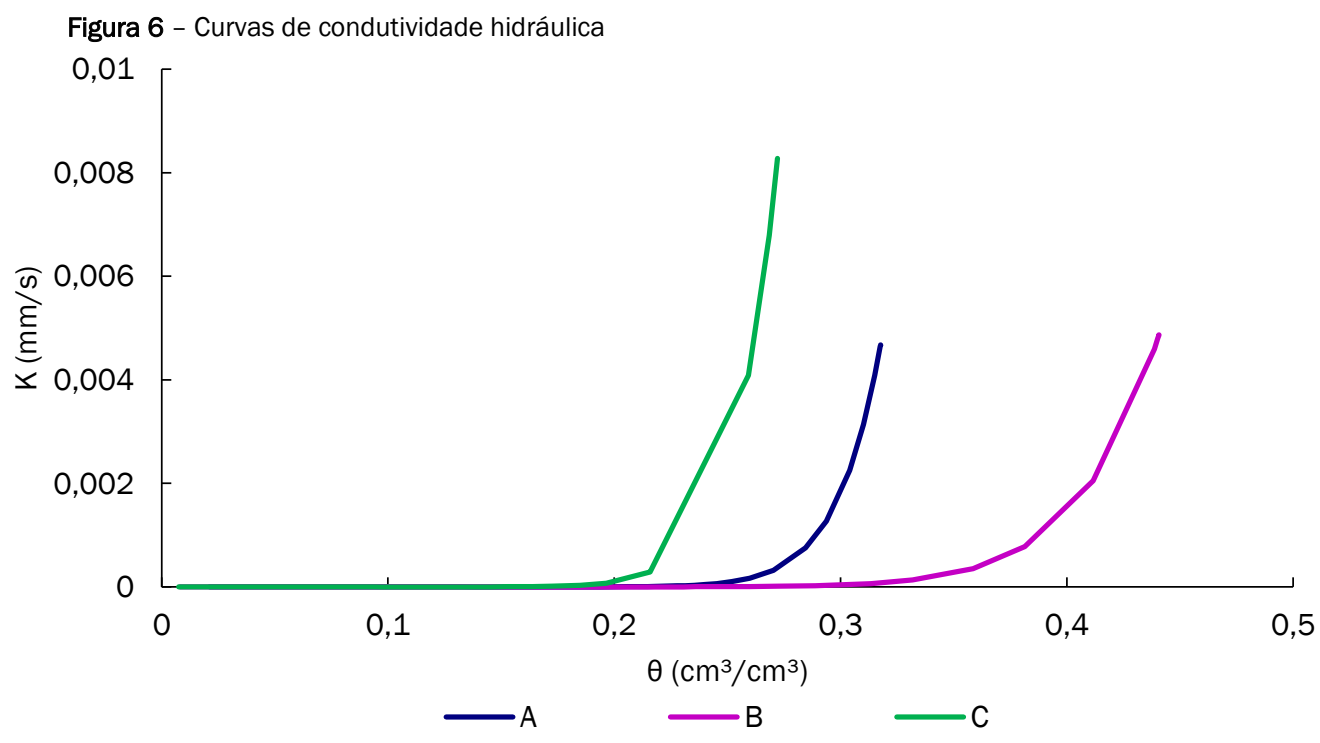

\subsection{Simulação computacional no software Hydrus 1D}

Após o uso do software RETC, comparando a Tabela 2 com a Tabela 3, observa-se que o parâmetro " $n$ " apresentou maiores valores e " $\mathrm{m}$ " menores valores para a hipótese de Burdine (1953), corroborando com os estudos feitos por Van Genuchten (2018) ao comparar as hipóteses de Burdine (Equação
1) e Mualem (Equação 3). O parâmetro de forma " $n$ " tem influência na inclinação da curva de retenção, já o "m" influencia na inflexão e no patamar mínimo dessa mesma curva (VAN GENUCHTEN, 1980). Sendo assim, a curva de retenção tende a se apresentar menos íngreme quando calculada através da hipótese de Mualem. 
Tabela 3 - Parâmetros da curva de retenção após a mudança da hipótese de Burdine (1953) para Mualem (1976) no software RETC

\begin{tabular}{ccccc}
\hline Pontos & $\theta_{\mathrm{r}}\left(\mathrm{cm}^{\mathbf{3}} / \mathrm{cm}^{3}\right)$ & $\theta_{\mathrm{s}}\left(\mathrm{cm}^{3} / \mathrm{cm}^{3}\right)$ & $\mathrm{n}$ & $\mathrm{m}$ \\
\hline A & 0,0059 & 0,3215 & 1,1603 & 0,1381 \\
B & 0,0045 & 0,4460 & 1,2218 & 0,1815 \\
C & 0,0024 & 0,2764 & 1,1837 & 0,1552 \\
\hline
\end{tabular}

Onde:

Or - umidade volumétrica residual;

Өs - umidade volumétrica na saturação; $\mathrm{n}$ - parâmetro de forma;

m - parâmetro de forma.

As simulações foram executadas para os três pontos a fim de verificar a resposta desse solo perante a variabilidade das suas condições hidrodinâmicas. A viabilidade da área permeável na atenuação do alagamento, constituída por uma camada de um metro de profundidade de solo natural, foi analisada a partir do conteúdo volumétrico de água nesse solo (Figura 7).

Figura 7 - Variação do conteúdo volumétrico de água em cada ponto do terreno sob condições de diferentes precipitações diárias ocorridas no mês de julho de 2000

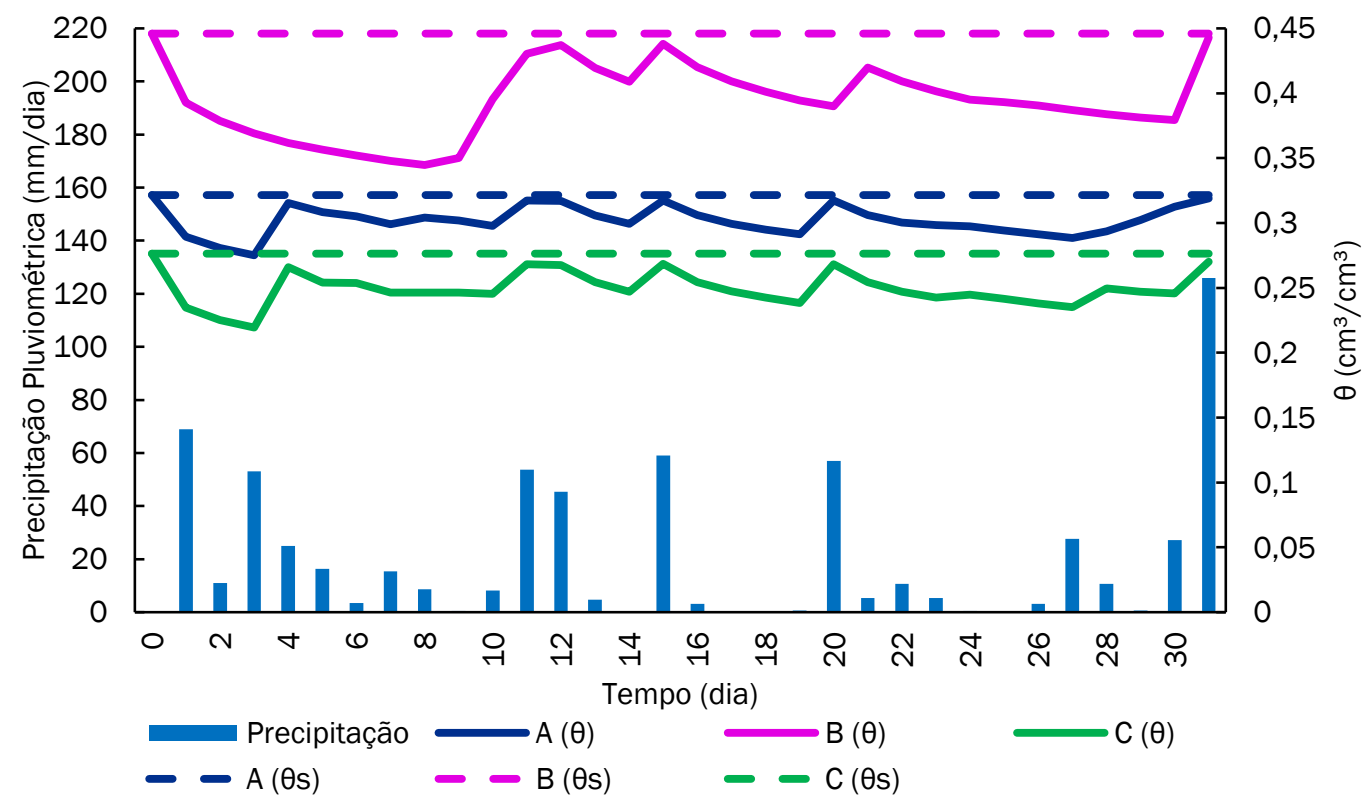

A variação do conteúdo de água $(\theta)$ a cada 24 horas para os pontos $\mathrm{A}, \mathrm{B}$ e $\mathrm{C}$ na profundidade de $1 \mathrm{~m}$, conforme a variação diária real de precipitação, foi exibida na Figura 7. As respostas das demais profundidades não foram exibidas devido à constituição do solo, ou seja, com a análise das respostas da simulação, notou-se que, independentemente das diferentes umidades volumétricas iniciais adotadas, há uma estabilização e homogeneização do comportamento em todas as profundidades após pouco tempo (entre o segundo e terceiro dia). Além disso, é demonstrada a umidade volumétrica saturada $\left(\theta_{\mathrm{s}}\right)$ para cada ponto a fim de avaliar se a capacidade de armazenamento do solo foi atingida.

No tempo zero de simulação, como condição inicial, foi imposto que todos os pontos apresentavam umidade volumétrica igual as suas respectivas $\theta_{\text {s. }}$ Notou-se uma semelhança na configuração das curvas dos pontos $\mathrm{A}$ e $\mathrm{C}$. Porém, no ponto $B$, destacam-se a maior capacidade drenante entre o $3^{\circ}$ e $11^{\circ}$ dias e na rápida capacidade de retenção entre o $30^{\circ}$ e $31^{\circ}$ dias. Esse comportamento hidráulico heterogêneo não pode ser explicado pela textura do solo, dado que $\mathrm{B}$ e $\mathrm{C}$ possuem a mesma classificação franco arenosa, e tão pouco pela densidade do solo, devido às diferenças terem se apresentado tanto na capacidade drenante como na de retenção. Logo, tal comportamento pode ser ocasionado pela heterogeneidade da estrutura dos poros e provável ativação dos seus poros hidraulicamente ativos, assim como foi verificado também por Souza et al. (2016).

Os diferentes valores de condutividade hidráulica saturada (Tabela 2), estimados para os pontos, interferem quantitativamente na água drenada desse solo. Este fato fica evidente ao comparar a maior redução volumétrica no ponto $\mathrm{C}\left(\mathrm{K}_{\mathrm{s}}=\right.$ $0,0083 \mathrm{~mm} / \mathrm{s})$ em relação ao ponto $A\left(K_{\mathrm{s}}=0,0047 \mathrm{~mm} / \mathrm{s}\right)$, considerando um mesmo intervalo de tempo. A título de exemplo, pode-se evidenciar as respostas, em relação à $1 \mathrm{~cm}^{3} \mathrm{de}$ solo, entre o dia zero e o $3^{\circ} \mathrm{dia}$, quando o ponto $\mathrm{A}$ apresentou uma redução de $0,04641 \mathrm{~cm}^{3}$ de água e C de 0,05696 $\mathrm{cm}^{3}$.

Em diferentes instantes $\left(4^{\circ}, 11^{\circ}, 12^{\circ}, 15^{\circ}, 20^{\circ}\right.$ e $31^{\circ}$ dias $)$ e para cada ponto, a umidade volumétrica aproxima-se da $\theta_{\mathrm{s}} \mathrm{e}$ aumenta a possibilidade de geração de escoamento superficial, como concluído também por Assouline (2013). É exibido na Figura 8, de forma percentual, o conteúdo de água no solo, com relação aos respectivos $\theta_{\mathrm{s}}$. A análise demonstra a boa resposta da área permeável perante os eventos. 
Figura 8 - Percentual do conteúdo volumétrico de água com relação à umidade volumétrica saturada.

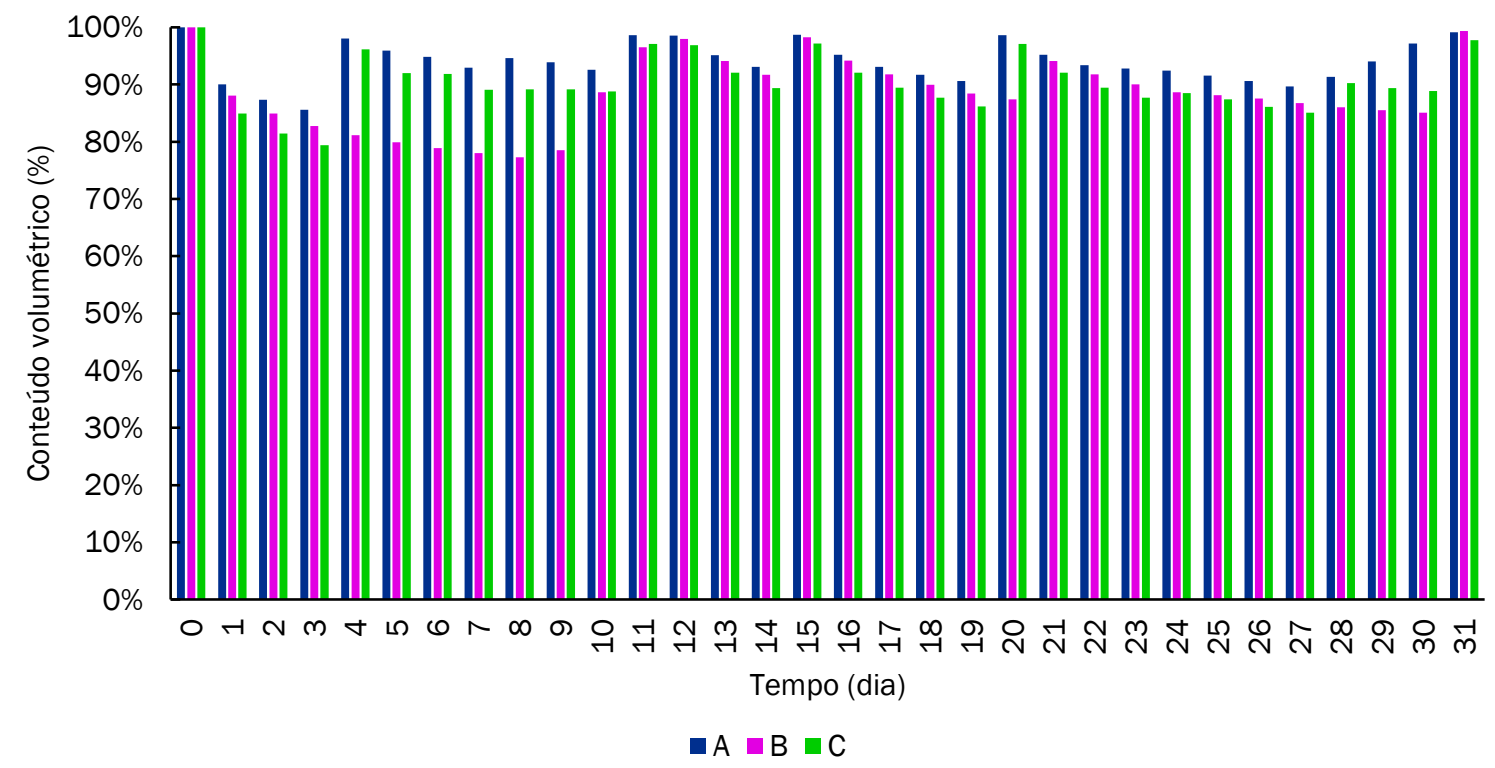

Porém, foi possível afirmar que o ponto A apresentou uma condição mais desfavorável, pois atinge maiores percentuais de conteúdo de água, com relação à $\theta_{\mathrm{s}}$, durante 30 dias, dentre os 31 analisados. No $31^{\circ}$ dia, o ponto A e B apresentaram percentuais semelhantes de conteúdo volumétrico (99\%).

Como consequência dessa condição, efetivaram-se simulações com o ponto A, também no Hydrus 1D, com o intuito de estimar os valores de precipitações para os quais o solo atingiria o valor de $0,3215 \mathrm{~cm}^{3} / \mathrm{cm}^{3}$ (Tabela 3), correspondente ao seu $\theta_{\mathrm{s}}$, em qualquer horário do dia em análise (Figura 9), ou seja, não necessariamente nos tempos múltiplos de $24 \mathrm{~h}$. Entre $04^{\circ}$ e $30^{\circ}$ dias há uma tendência de estabilidade no valor de precipitação (acumulado predominante de 74,4 $\mathrm{mm}$ ) que gera um conteúdo volumétrico igual a $\theta_{\text {s. }}$ Fato diferente é evidenciado nos $1^{\circ}, 2^{\circ}, 3^{\circ}$ e $31^{\circ}$ dias.

Figura 9 - Precipitação simulada que gera o início da saturação do solo no ponto A

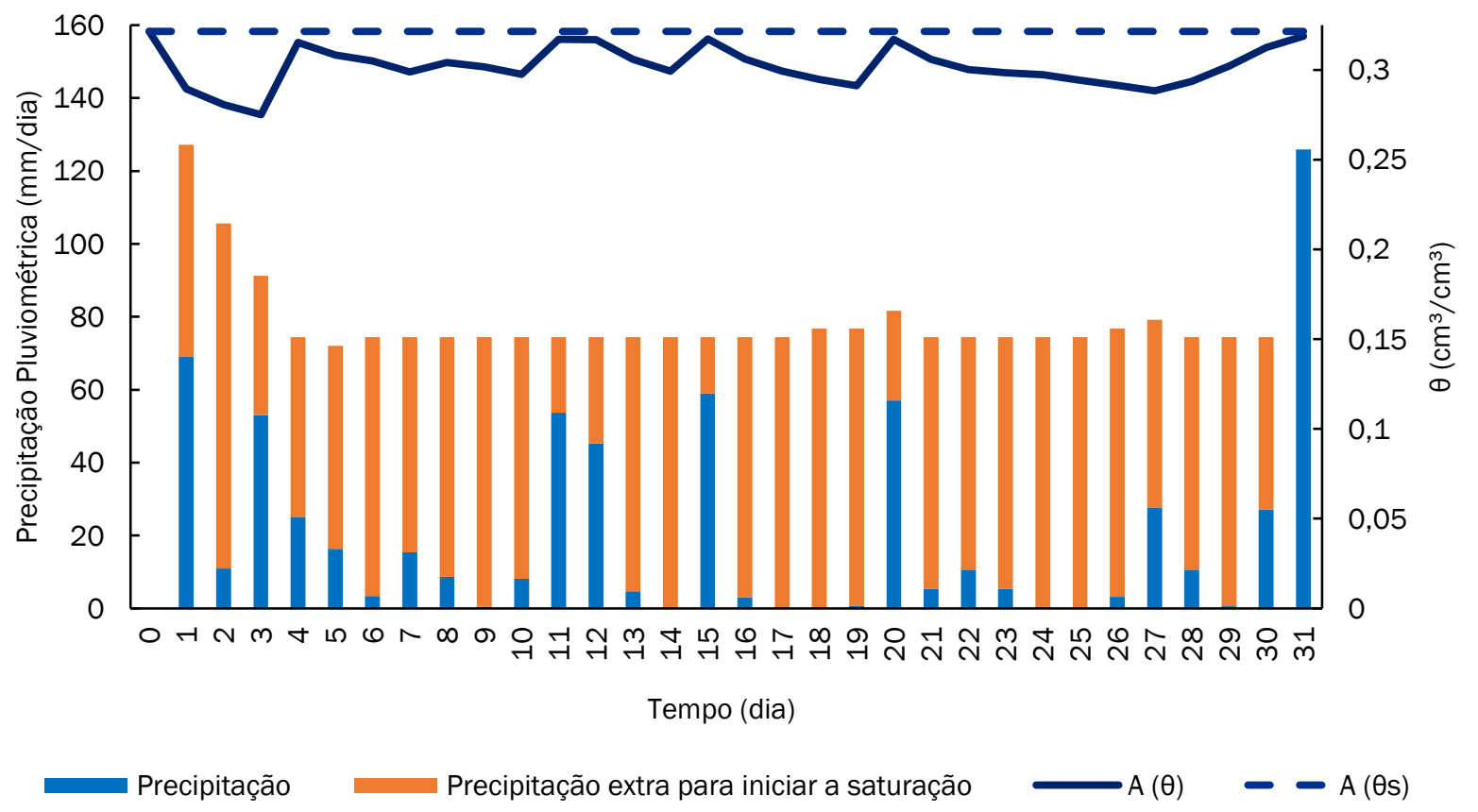

Apesar de existir uma tendência na precipitação que satura o solo $(74,4 \mathrm{~mm})$, alguns fatores podem influenciar neste valor. No $20^{\circ}$ dia, percebeu-se que a saturação do solo se daria com uma precipitação pluviométrica acumulada de $81,6 \mathrm{~mm}$, ou seja, 9,7\% (7,2 $\mathrm{mm})$ acima do valor predominante. Este fato pode ser justificado pela combinação das variações entre as demais condições meteorológicas (temperatura máxima, tem peratura mínima, umidade, velocidade do vento e insolação), 
também informadas como dados de entrada no Hydrus 1D.

Nos três primeiros dias, a condição de saturação adotada como umidade inicial na profundidade de $1 \mathrm{~m}$, associada à alta capacidade drenante para atingir o equilíbrio de comportamento das diferentes profundidades (entre o segundo e terceiro dia), podem explicar os valores mais elevados de precipitação suportados pelo solo para atingir a saturação a qualquer instante. Já no último dia, a precipitação real acumulada de $125,9 \mathrm{~mm}$ foi suficiente para ocasionar frequentes momentos de saturação, mais precisamente entre os tempos de $726,8 \mathrm{~h}$ até $741,4 \mathrm{~h}$. Após esse intervalo, houve uma recuperação do solo conforme seu aumento na capacidade de drenagem que resultou na diminuição da umidade para 0,3188 $\mathrm{cm}^{3} / \mathrm{cm}^{3}$ no tempo de $744 \mathrm{~h}$. Uma nova simulação mostrou que a precipitação de $74,4 \mathrm{~mm}$ /dia seria suficiente para iniciar a saturação do solo em qualquer instante desse último dia.
Além disso, através das respostas simuladas sobre o fluxo de água na base da camada do solo, foi possível analisar o fluxo real de água na parte inferior do solo (Figura 10) e perceber um comportamento proporcional com o conteúdo volumétrico (Figura 7). Ou seja, quanto maior for a umidade do solo $(\theta)$, maior será o fluxo de água na base dessa camada. Uma consequência importante desse fluxo é a recarga dos aquíferos. Além de influenciar, em alguns casos, na manutenção do abastecimento de água realizado através de águas subterrâneas, o rebaixamento do nível freático pode ocasionar depressões em terrenos e impactar as construções civis do Recife. Fato semelhante foi constatado por Ledoux (1995) com a seca ocorrida na França em 1990, ano em que os valores pagos pelas seguradoras, devido a degradação dos imóveis, como fissuras e recalques, corresponderam as dobro daqueles pagos pelos impactos na agricultura.

Figura 10 - Fluxo real de água na parte inferior do solo em cada ponto do terreno sob condições de diferentes precipitações diárias ocorridas no mês de julho de 2000

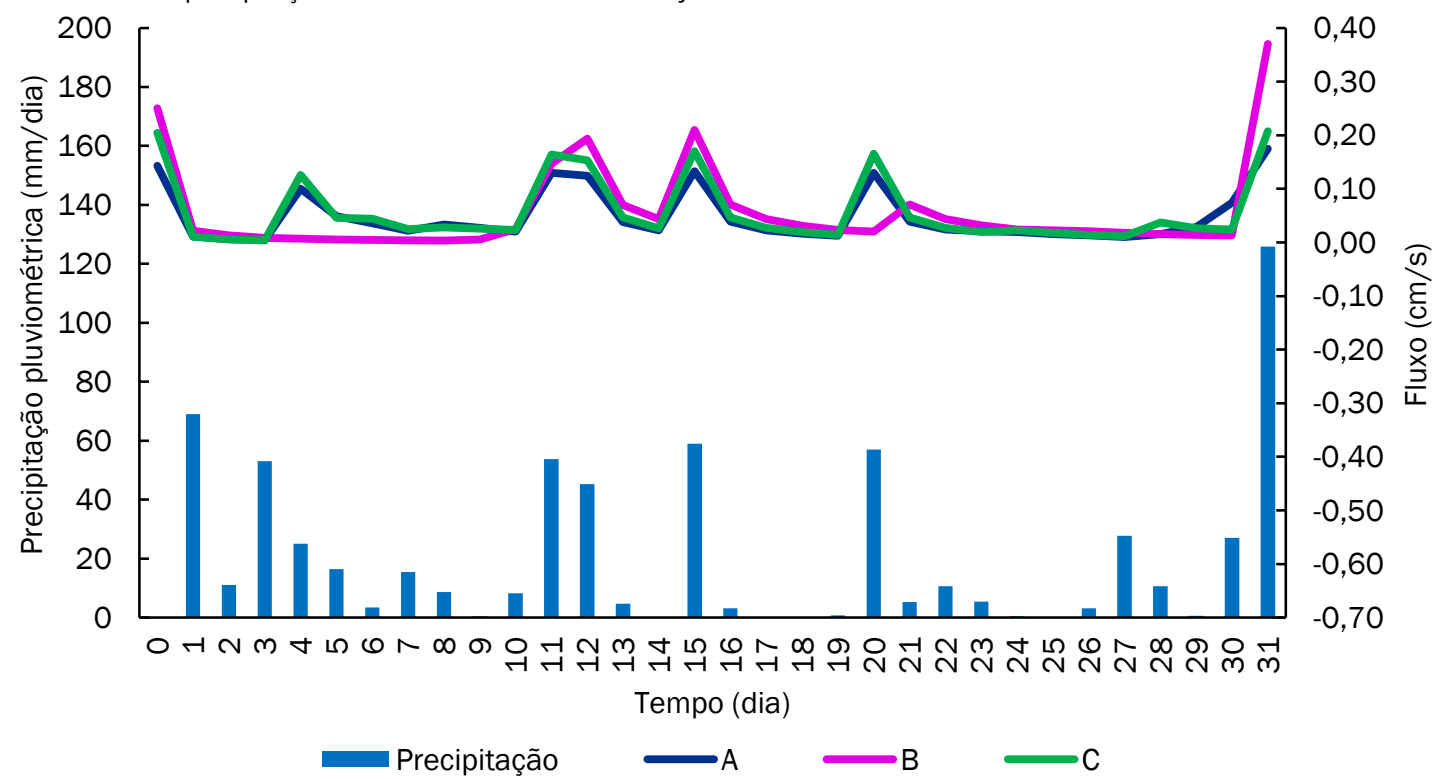

\section{CONCLUSÕES}

Durante a escolha do ponto crítico, muitos, dentre os 159 pontos, foram descartados pela ausência de área próxima disponível para o estudo da capacidade de infiltração do solo, devido à grande urbanização da cidade. Dessa forma, a região selecionada para estudo está localizada no bairro de Areias e possui um terreno de, aproximadamente, $9.000 \mathrm{~m}^{2}$. Neste local, o cenário de alagamento é recorrente em épocas chuvosas.

A determinação das características hidrodinâmicas do solo constatou uma variação da classificação textural entre franco argilo arenoso e franco arenoso. A condutividade hidráulica saturada estimada, parâmetro de maior variação, apresentou valor máximo de $0,0083 \mathrm{~mm} / \mathrm{s}$ e mínimo de $0,0047 \mathrm{~mm} / \mathrm{s}$. Para mais, o solo estudado apresentou boa capacidade de infiltração e consequente capacidade para atenuação de alagamento.
A partir da simulação da dinâmica da água no software Hydrus, observou-se que, independentemente da umidade inicial da profundidade analisada, a constituição homogênea do solo tende a estabilizar seu comportamento ao longo de toda a camada em um curto período de tempo. Em geral, os valores estimados de condutividade hidráulica influenciam de forma proporcional na capacidade drenante do solo, porém, a estrutura do mesmo pode ocasionar uma resposta discrepante em relação ao esperado.

Por fim, ao verificar a possibilidade de ocorrência da recarga do nível freático, notou-se um comportamento proporcional do fluxo de água com o conteúdo volumétrico do solo e vantagens com relação ao abastecimento humano e seguridade das obras civis.

\section{REFERÊNCIAS}

ABNT - Associação Brasileira de Normas Técnicas. NBR 7181: Solo-análise granulométrica. 2016. 
ABREU, S. L.; REICHERT, J. M.; SILVA, V. R.; REINERT, D. J.; BLUME, E. Variabilidade espacial de propriedades físico-hídricas do solo, da produtividade e da qualidade de grãos de trigo em Argissolo Franco Arenoso sob plantio direto. Ciência Rural, v. 33, n. 2, 2003.

https://doi.org/10.1590/S0103-84782003000200015

ALVES, E. M.; NETTO, A. M.; ANTONINO, A. C. D.; LIMA, J. R. S. Simulação da dinâmica da água em solo cultivado com feijão caupi no brejo paraibano. Revista Brasileira de Recursos Hí dricos, v. 17, n. 3, 2012.

https://doi.org/10.21168/rbrh.v17n3.p175-186

ANTONELI, V.; THOMAZ, E. L. Comparação de infiltração de água no solo mensurada em período seco e úmido, em diferentes usos da terra na bacia do arroio Boa Vista, Guamiranga, Paraná. Revista Ambiência, v. 5, n. 2, p. 301 - 318, 2009.

ASSOULINE, S. Infiltration into soils: Conceptual approaches and solutions. Water Resources Research, v. 49, n. 4, 2013. https://doi.org/10.1002/wrcr.20155

BAGARELLO, V.; IOVINO, M.; ELRICK, D. A Simplified Falling Head Technique for Rapid Determination of Field Saturated Hydraulic Conductivity. Soil Science Society of America Journal. v. 68, n. 1, 2004.

https://doi.org/10.2136/sssaj2004.0066

BOSCH, D. D.; WEST, L. T. Hydraulic conductivity variability for two sandy soils. Soil Science Society of America Journal, Madison, v. 62, n. 1, p. 90-98, 1998.

https://doi.org/10.2136/sssaj1998.03615995006200010 $\underline{012 x}$

BRADY, N. C. Natureza e propriedades dos solos. 7. ed. Rio de Janeiro: F. Bastos, 1989. 898 p.

BROOKS, R.H.; COREY, A.T. Hydraulic properties of porous media. Hydrology Paper, v.3, Colorado State Univ. Fort Collins, 1964.

BURDINE, N. T. Relative permeability calculations from pore size distribution data. Journal of Petroleum Technology. v. 5 , n. 03, p. 71-78, 1953. https://doi.org/10.2118/225-G

CAMARGO, A. O.; ALLEONI, L. R. F. Compactação do solo e o desenvolvimento das plantas. Piracicaba: Esalq, p. 132, 1997.

CAMPANA, N. A.; TUCCI, C. E. M. Predicting floods from urban development scenarios: case study of Dilúvio Basin, Porto Alegre, Brazil. Urban Water, v 3, p 113-124, 2001

https://doi.org/10.1016/S1462-0758(01)00004-8

COUTINHO, A. P.; LASSABATÈRE, L.; MONTENEGRO, S.; ANTONINO, A. C. D.; ÂNGULO-JARAMILLO, R.; CABRAL, J.J.S.P. Hydraulic characterization and hydrological behaviour of a pilot permeable pavement in an urban centre, Brazil. Hydrological Processes, v. 30, n. 23, 2016.

https://doi.org/10.1002/hyp.10985

DI PRIMA, S.; LASSABATÈRE, L.; BAGARELLO, V.; IOVINO, M.; ANGULO-JARAMILO. Testing a new automated single ring infiltrometer for Beerkan infiltration experiments. Geoderma, v. 262, p. 20-34, 2016.

https://doi.org/10.1016/i.geoderma.2015.08.006

EMBRAPA. Centro nacional de pesquisa de solos. Manual de métodos de análise de solo. Embrapa, 2017.

EMLURB. Relatório de Andamento do RAP - Caracterização da Área de Influência Direta - AID. In: Estudo elaboração dos estudos de concepção para gestão e manejo de águas pluviais e drenagem urbana do Recife. Recife, out. 2013.

FABRICIO, E. P.; BRUM, N.D.; PINTO, R. B.; KÖHLER, F. S. Planejamento urbano sustentável. Brazilian Journal of Development, v. 5, n. 2, p. 1326-1338, 2019.

FRIZZONE, J.A. Irrigação por superfície. São Paulo: ESALQ/ USP. 1993. $183 p$.

GOMES, D. O.; RODRIGUES, C. A.; COSTA, A. N.; ALMEIDA, L. B.; FERNANDES, F. P. S.; PONTES JUNIOR, B.; SATO, M.K.; VIEIRA, D.C.; PEDROSO, A. J. S. Efeito de diferentes níveis de compactação sobre a porosidade, micro e macroporosidade em solos de texturas distintas. In: Ensaios nas Ciências Agrárias e Ambientais 5. Paraná: Atena Editora, 2019. P. 83-88. https://doi.org/10.22533/at.ed.4141916019

GUO, J. C. Y. Green Concept in Storm Water Management. Irrigation \& Drainage Systems Engineering, [S. I.], v. 2, n. 3, p.18, 2013. https://doi.org/10.4172/2168-9768.1000114

HAVERKAMP, R.; ROSS, P.J.; SMETTEM, K.R.J.; PARLANGE, J.Y. Three dimen-sional analysis of infiltration from the disc infiltrometer 2. Physically based infiltration equation. Water Resources Research. v. 30, p. 2931-2935, 1994. https://doi.org/10.1029/94WR01788

HILLEL, D. Environmental soil physics. New York: Academic Press. 771p., 1998.

ISTOK, J. D.; BLOUT, D. O.; BAKER, L.; JOHNEJACK, K.R.; HAMMERMEISTER, D. P. Spatial variability in alluvium properties at a low-level nuclear waste site. Soil Science Society of America Journal, Madison, v. 58, n. 4, p. 1040-1051, 1994.

https://doi.org/10.2136/sssaj1994.03615995005800040 $007 x$

JONES, C. A. Effect of soil texture on critical bulk densities for root growth. Soil Science Society of America Journal, v. 47, n. 6, p. 1208-1211, 1983.

https://doi.org/10.2136/sssaj1983.03615995004700060 $\underline{029 x}$

KLEIN, V.A.; LIBARDI, P.L. Faixa de umidade menos limitante ao crescimento vegetal e sua relação com a densidade do solo ao longo do perfil de um Latossolo Roxo. Ciência Rural, v. 30, n. 6,2000 . https://doi.org/10.1590/S010384782000000600006

LASSABATÈRE, L.; ANGULO-JARAMILLO, R.; UGALDE, J. M. S.; CUENCA, R.; BRAUD, I.; HAVERKAMP, R. Beerkan estimation of soil transfer parameters through infiltration experiments BEST. Soil Science Society of America Journal. v. 70, n. 2, p. 521-532, 2006. https://doi.org/10.2136/sssaj2005.0026

LATORRE, B.; MORET-FERNÁNDEZ, D. Simultaneous estimation of the soil hydraulic conductivity and the van Genuchten water retention parameters from an upward infiltration experiment. Journal of Hydrology, v. 572, p. 461-469, 2019. https://doi.org/10.1016/i.jhydrol.2019.03.011

LEDOUX, Bruno. Les catastrophes naturelles en France. Payot, 1995. https://doi.org/10.4267/2042/51990 
LIANG, X.; LIAKOS, V.; WENDROTH, O.; VELLIDIS, G. Scheduling irrigation using an approach based on the van Genuchten model. Agricultural Water Management, v. 176, p. 170-179, 2016. https://doi.org/10.1016/j.agwat.2016.05.030

LUO, Z.; KONG, J.; SHEN, C.; LU, C.; HUA, G.; ZHAO, Z.; ZHAO, $\mathrm{H}$.; LI, L. Evaluation and application of the modified van Genuchten function for unsaturated porous media. Journal of Hydrology, v. 571, p. 279-287, 2019.

https://doi.org/10.1016/i.jhydrol.2019.01.051

MANRIQUE, L. A.; JONES, C. A. Bulk density of soils in relation to soil physical and chemical properties. Soil Science Society of America Journal, v. 55, n. 2, p. 476-481, 1991. https://doi.org/10.2136/sssaj1991.03615995005500020 $\underline{030 x}$

MELO, T.A.T.; COUTINHO, A.P.; CABRAL, J.J.S.P.; ANTONINO, A.C.D.; CIRILO, J.A. Jardim de chuva: sistema de biorretenção para o manejo das águas pluviais urbanas. Ambiente Construído. v. 14, n. 4, p. 147-165, 2014. https://doi.org/10.1590/S1678-86212014000400011

MESQUITA, M. G. B.; MORAES, S. O. A dependência entre a condutividade hidráulica saturada e atributos físicos do solo. Ciência Rural, v. 34, n. 3, p. 963 - 969, 2004. https://doi.org/10.1590/S0103-84782004000300052

MOLINA, A. M. C.; ENOUT, H. J. R.; REDA, A. L. Sistemas de drenagem em praças, parques e outras áreas peatonais urbanas visando amortecer inundações. Revista Mackenzie de Engenharia e Computação, v. 18, n. 1, 2018.

MONTENEGRO, A.A.A.; MONTENEGRO, S. M. G. L. Variabilidade espacial de classes de textura, salinidade e condutividade hidráulica de solos em planície aluvial. Revista Brasileira de Engenharia Agrícola e Ambiental, v. 10, n. 1, p. 30-37, 2006. https://doi.org/10.1590/S1415-43662006000100005

MOURA, E. F. S.; SILVA, S. R. Estudo do grau de impermeabilização do solo e propostas de técnicas de drenagem urbana sustentável em área do Recife-PE. Revista Nacional de Gerenciamento de Cidades, v. 3, n. 15, 2015.

https://doi.org/10.17271/231884723152015993

MUALEM, Y. A new model for predicting the hydraulic conductivity of unsaturated porous media. Water resources research. v. 12 , n. 3, p. 513-522, 1976.

https://doi.org/10.1029/WR012i003p00513

NAZEM, M. N. I.; HASSAN, M. M. Examination of land use/land cover changes, urban growth dynamics, and environmental sustainability in Chittagong city, Bangladesh. Environment, Development and Sustainability, v 18, p 697-716, 2016. https://doi.org/10.1007/s10668-015-9672-8

NIEHOFF, D.; BRONSTERT, A., BURGER, G. Effects of climate and land-use change on storm runoff generation: present knowledge and modelling capabilities. Hydrologic Processes, v 16, p 509-529, 2002. https://doi.org/10.1002/hyp.326

PACHECO, F.B.P.; REICHARDT, K.; TUON, R.L. Variabilidade espacial e temporal do potencial mátrico da água em terra roxa estruturada. Scientia Agricola, v. 51, n. 2, p. 327-334, 1994. https://doi.org/10.1590/S0103-90161994000200020

PATIL, N. G.; SINGH, S. K. Pedotransfer Functions for Estimating Soil Hydraulic Properties: A Review. Pedosphere. v. 26, n.
4, p. $417-430,2016$. https://doi.org/10.1016/S10020160(15)60054-6

PIRKHOFFER E.; CZIGÁNY S.; GERESDI I. Impact of rainfall pattern on the occurrence of flash floods in Hungary Z. Geomorph, v 53, p 139-157, 2009. https://doi.org/10.1127/03728854/2009/005353-0139

REZENDE, F. C.; SCALOPPI, E. J. Avaliação de métodos para determinação das características de infiltração em sulcos. Pesquisa Agropecuária Brasileira, v. 20, n. 2, p. 227-233, 1985.

ROSOLEM, C. A.; FOLONI, J. S. S.; TIRITAN, C. S. Root growth and nutrient accumulation in cover crops as affected by soil compaction. Soil Tillage Research, v.65, p.109-115, 2002 https://doi.org/10.1016/S0167-1987(01)00286-0

SALES, E. G.; ALMEIDA, C. N. Impacto das culturas da cana-deaçúcar e do abacaxi nas propriedades hidrodinâmicas do solo da Bacia do Rio Gramame - PB. Revista Águas Subterrâneas. Resumo de dissertações e teses, p. 1 - 1, 29 maio 2015.

SANTOS, C. A.G.; SILVA, J. F. C. B. C.; SILVA, R. M. Caracterização hidrodinâmica dos solos da bacia experimental do riacho Guaraíra utilizando o método Beerkan. Revista Brasileira de Recursos Hídricos. v. 17, n. 4, p. 149-160, 2012. https://doi.org/10.21168/rbrh.v17n4.p149-160

SANTOS, D. P.; MONTENEGRO, A. A. A.; RODRIGUES, R. A. S.; ARAÚJO, D. C. S.; SANTOS, C. S.; CRUZ NETO, J. F. Variabilidade espacial de atributos físicos do solo em vale aluvial na região de Pernambuco. Revista Brasileira de Agricultura Irrigada. v. 12, p. 2271-2282, 2018.

https://doi.org/10.7127/rbai.v12n100647

SANTOS, K. S.; MONTENEGRO, A. A. A.; ALMEIDA, B. G.; MONTENEGRO, S. M. G. L.; ANDRADE, T. S.; FONTES JÚNIOR, R. V. $P$. Variabilidade espacial de atributos físicos em solos de vale aluvial no semiárido de Pernambuco. Revista Brasileira de Engenharia Agrícola e Ambiental, v. 16, n. 8, p. 828-836, 2012. https://doi.org/10.1590/S1415-43662012000800003

SCHIFMAN, L. A.; SHUSTER, W. D. Comparison of Measured and Simulated Urban Soil Hydrologic Properties. Journal of Hydrologic Engineering, v 24, 2019.

https://doi.org/10.1061/(ASCE)HE.1943-5584.0001684

SEPASKHAH, A. R.; ATAEE, J. A simple model to determine saturated hydraulic conductivity for large scale subsurface drainage. Biosystems engineering, v. 89, n. 4, p. 505-513, 2004. https://doi.org/10.1016/i.biosystemseng.2004.08.013

SHENG, J.; HUANG, T.; YE, Z.; HU, B.; LIU, Y.; FAN, Q. Evaluation of van Genuchten-Mualem model on the relative permeability for unsaturated flow in aperture-based fractures. Journal of Hydrology, 2019.

https://doi.org/10.1016/i.jhydrol.2019.06.047

SHUSTER, W.D.; DADIO, S.; DROHAN, P.; LOSCO, R.; SHAFFER, J. Residential demolition and its impact on vacant lot hydrology: Implications for the management of stormwater and sewer system overflows. Landscape Urban Plann, v 125, p 48-56, 2014.

https://doi.org/10.1016/i.landurbplan.2014.02.003

SILVA JUNIOR, M.A.B.; SILVA, S.R.; SOARES, W.A. Parâmetros de infiltrabilidade em solo urbano para modelo chuva-vazão. 
Periódico Eletrônico Fórum Ambiental da Alta Paulista, v. 12, n. 3, 2016.

https://doi.org/10.17271/1980082712320161417

SIMUNEK, J., ŠEJNA, M., SAITO, H., SAKAI, M., VAN GENUCHTEN, M. Th. The HYDRUS-1D Software Package for Simulating the One-Dimensional Movement of Water, Heat, and Multiple Solutes in Variably Saturated Media. RIVERSIDE, CALIFORNIA, 373 p., 2013.

SOARES, W. A. Determinação dos parâmetros hídricos do solo por meio da simulação computacional do processo de infiltração. Revista Diálogos: Revista de Estudos Culturais e da Contemporaneidade. v. 1, n. 3, p. 73-84, 2010. https://doi.org/10.13115/2236-1499.2010v1n3p73

SOBIERAJ, J. A.; ELSENBEER, H.; CAMERON, G. Scale dependency in spatial patterns of saturated hydraulic conductivity. Catena, v. 55, n. 1, p. 49-77, 2004.

https://doi.org/10.1016/S0341-8162(03)00090-0

SOUZA, E. S.; ANTONINO, A. C. D.; ANGULO-JARAMILLO, R.; NETTO, A. M. Caracterização hidrodinâmica de solos: Aplicação do método Beerkan1. Revista Brasileira de Engenharia Agrícola Ambiental. v. 12, n. 2, p. 128-135, 2008. https://doi.org/10.1590/S1415-43662008000200004

SOUZA, E. S.; ANTONINO; A. C. D.; NETTO, A. M.; SOUZA, R. M. S.; GONDIM, M. V. S.; LIMA; V. F.; LIMA; J. R. S.; ALVES, E. M.; COUTINHO, A. P.; SOARES, W. A. Comportamento hidrodinâmico de solos em cultivos de vazante no semiárido de Pernambuco. Journal of Environmental Analysis and Progress, v. 1, n. 1, p. 52-60, 2016.

https://doi.org/10.24221/jeap.1.1.2016.984.52-60

STRECK, C. A.; REINERT, D. J.; REICHERT, J. M.; KAISER, D. R. Modificações em propriedades físicas com a compactação do solo causada pelo tráfego induzido de um trator em plantio direto. Ciência Rural, v.34, n. 3, 2004.

https://doi.org/10.1590/S0103-84782004000300016

TIAN, Z.; KOOL, D.; REN, T.; HORTON, R. HEITMAN, J. L. Approaches for estimating unsaturated soil hydraulic conductivities at various bulk densities with the extended Mualem-van Genuchten model. Journal of Hydrology, v. 572, p. 719-731, 2019. https://doi.org/10.1016/j.jhydrol.2019.03.027
UNITED NATIONS. World urbanization prospects: the 2007 Revision. Unied Nations Department of Economic and Social Affairs. Population Division, 2008.

URSULINO, B. S.; MONTENEGRO, S. M. G. L.; COUTINHO, A. P.; COELHO, V. H. R.; ARAÚJO, D. C. S.; GUSMÃO, A. C. V.; SANTOS NETO, S. M.; LASSABATERE, L.; ANGULO-JARAMILLO, R. Modelling soil water dynamics from soil hydraulic parameters estimated by an alternative method in a tropical experimental basin. Water, v. 11, n. 5, p. 1007, 2019. https://doi.org/10.3390/w11051007

VAN GENUCHTEN, M. A closed-form equation for predicting the hydraulic conductivity of unsaturated soils. Soil Science Society of America Journal. v. 44, n. 5, p.892-898, 1980. https://doi.org/10.2136/sssaj1980.03615995004400050 $\underline{002 x}$

VAN GENUCHTEN, M. T.; LEIJ, F. J.; YATES, S. R. The RETC code for quantifying the hydraulic functions of unsaturated soils. 1991.

VIEIRA, S. R.; NIELSEN, D. R.; BIGGAR, J. W. Spatial Variability of Field-Measured Infiltration Rate 1. Soil Science Society of America Journal, v. 45, n. 6, p. 1040-1048, 1981. https://doi.org/10.2136/sssaj1981.03615995004500060 $\underline{007 x}$

WALKER, W. R.; SKOGERBOE, G. V. Surface irrigation. Theory and practice. Prentice-Hall, 1987.

WALLOR, E.; ROSSKOPF, N.; ZEITZ, J. Hydraulic properties of drained and cultivated fen soils part I-Horizon-based evaluation of van Genuchten parameters considering the state of moorsh-forming process. Geoderma, v. 313, p. 69-81, 2018. https://doi.org/10.1016/j.geoderma.2017.10.026

WARRICK, A. W.; NIELSEN, D. R. Spatial variability of soil physical properties in the field. Application of soil physics., p. 319344, 1980. https://doi.org/10.1016/B978-0-12-3485809.50018-3

WOODBURY, A. D.; SUDICKY, E. A. The geostatistical characteristics of the Borden aquifer. Water Resources Research, v. 27, n. 4, p. 533-546, 1991.

https://doi.org/10.1029/90WR02545 